\title{
Research on the Design of the Core Ploughshare Furrow Opener Based on the Discrete Element Method*
}

\author{
Shiqiang Pan ${ }^{1,2, a}$, Zifu $\mathrm{CaO}^{2, \mathrm{~b}}$, Yulin Yang ${ }^{2, \mathrm{c}}$, Jianqun $\mathrm{Yu}^{1, \mathrm{~d},{ }^{*}}$ \\ ${ }^{1}$ College of Biological and Agricultural Engineering, Jilin University, Changchun 130025 \\ ${ }^{2}$ College of Engineering and Technology, Jilin Agricultural University, Changchun 130118

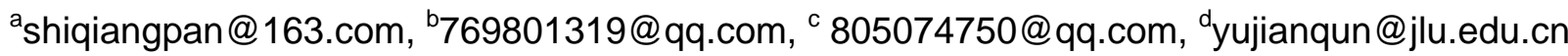 \\ ${ }^{*}$ Corresponding author.
}

Keywords: Core ploughshare, Furrow opener, DEM

\begin{abstract}
The furrow opener is the important working parts of the seeding machine. In this paper, we would design the furrow opener of core ploughshare based on many parameters such as the width, the penetrating clearance angle angle, the slope angle. A series of new opener was designed using the uniform design experiment method. Arable layer soil model was established using the discrete element method (DEM). We also revised the discrete element simulation model using the glass soil bin and the high-speed camera technology. The results of tests compared with discrete element simulation showed that both had the good correlation and the same laws. At the same time, the core furrow opener was optimization design. Its width was $50 \mathrm{~mm}$. The penetrating clearance angle was $50^{\circ}$. The slope angle was $55^{\circ}$.
\end{abstract}

\section{Introduction}

In northeast region, the furrow opener of core ploughshare was widely used, which was with simple structure, flat ditch, better buried performance, and less demanding on soil preparation before planting ${ }^{[1]}$. However, the currently used furrow opener was ditching too large width with poor soil moisture; and the large passage of lateral soil is not suitable for high-speed seeding ${ }^{[2]}$. In this paper, the corresponding soil particle discrete element model is established through to the Jilin province in the central area of soil physics parameters measurement. The furrow opener of core ploughshare was designed using the uniform design experiment method. Three factors, eight levels were chosen as the experiment scheme. We finally obtained the optimal combination by many parameters of the opener.

\section{The determination of parameters of the furrow opener of core ploughshare}

Changing the opener main parameters(the width is $\mathrm{d}$, the penetrating clearance angle is $\alpha$, the slope angle is $\beta$ ), this experiment mainly could analysis the performance of the opener ${ }^{[3]}$. It was shown in figure 1 .
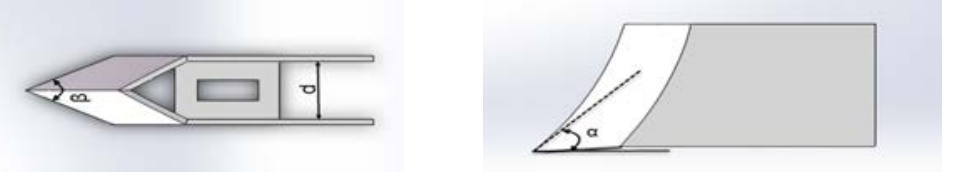

Fig 1 The Opener model

We would select the core ploughshare three main factors for the design parameters. Each factor chose 8 levels as shown in Table 1.

\footnotetext{
* Supportive fund: the National high-tech research and development program of 863 project(2006AA04Z125) and the international natural science fund project(11172112 and 51175219).
} 
Table 1 Factor levels table of the furrow opener

\begin{tabular}{ccc}
\hline the width $(\mathrm{cm})$ & the penetrating clearance angle $\left(^{\circ}\right)$ & the slope angle $\left(^{\circ}\right)$ \\
\hline 40 & 15 & 45 \\
50 & 20 & 50 \\
60 & 25 & 55 \\
70 & 30 & 60 \\
80 & 35 & 65 \\
90 & 40 & 70 \\
100 & 45 & 75 \\
110 & 50 & 80
\end{tabular}

According to uniform design experiment, 16 opener models of the different shape were designed. Experimental scheme was shown in Table $2^{[4]}$.

Table 2 Design factors table of the furrow opener

\begin{tabular}{cccc}
\hline Test number & the width $(\mathrm{cm})$ & the penetrating clearance angle $\left({ }^{\circ}\right)$ & the slope angle $\left({ }^{\circ}\right)$ \\
\hline 1 & $1(40)$ & $2(20)$ & $5(65)$ \\
2 & $1(40)$ & $4(30)$ & $2(50)$ \\
3 & $2(50)$ & $6(40)$ & $7(75)$ \\
4 & $2(50)$ & $8(50)$ & $3(55)$ \\
5 & $3(60)$ & $2(20)$ & $8(80)$ \\
6 & $3(60)$ & $4(30)$ & $5(65)$ \\
7 & $4(70)$ & $6(40)$ & $1(45)$ \\
8 & $4(70)$ & $8(50)$ & $6(70)$ \\
9 & $5(80)$ & $1(15)$ & $3(55)$ \\
10 & $5(80)$ & $3(25)$ & $8(80)$ \\
11 & $6(90)$ & $5(35)$ & $4(60)$ \\
12 & $6(90)$ & $7(45)$ & $1(45)$ \\
13 & $7(100)$ & $1(15)$ & $6(70)$ \\
14 & $7(100)$ & $3(25)$ & $2(50)$ \\
15 & $8(110)$ & $5(35)$ & $7(75)$ \\
16 & $8(110)$ & $7(45)$ & $4(60)$ \\
\hline
\end{tabular}

\section{The discrete element simulation analyze for the furrow opener of core ploughshare}

\section{The establishment of soil simulation model}

When soil particle model was set up, the part of the main parameters was determined based on the soil physical property of Jilin province central region. The other part of the parameters was obtained by contrast experiment and the simulation results after correction. We choose Hertz-Mindlin adhesive contact model that is consistent with the actual situation of soil ${ }^{[5]}$. We would observe the different size of soil particles shape using two-dimensional image instrument. These were shown in figure 2.
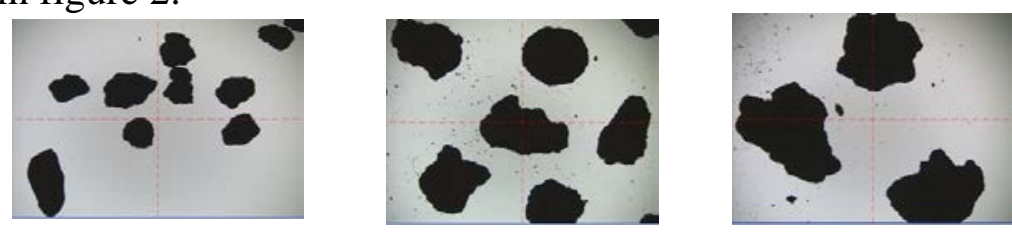

a) $0.5 \mathrm{~mm}-1 \mathrm{~mm}$ soil particles b) $1 \mathrm{~mm}-2 \mathrm{~mm}$ soil particles c) $2 \mathrm{~mm}-3 \mathrm{~mm}$ soil particles

Figure 2 The different size of soil particles two-dimensional images

In order to more real reflect the shape of the soil particles, soil particles were simulated the single sphere, double spheres and three spheres stack. 


\section{The simulation experiment of the furrow opener}

We separately carried through the opener working process simulation. We would observe the soil disturbance. Because the simulation opener sorts are more, we only provide two sets of furrowing simulation diagram. It was shown in Table 3. Simulation experiments show that the width of the opener is smaller; the back to the soil is more obvious. The width of the opener is bigger; the back to the soil is not obvious.

Table 3 The state diagram of simulating the opener

\begin{tabular}{cccccccccccccccccc}
\hline $\begin{array}{c}\text { Test } \\
\text { number }\end{array}$ & 1 & 2 & 3 & 4 & 5 & 6 & 7 & 8 & 9 & 10 & 11 & 12 & 13 & 14 & 15 & 16 \\
\hline $\begin{array}{c}\text { Horizontal } \\
\text { resistance } \\
(\mathrm{N})\end{array}$ & 31.94 & 31.7 & 32.48 & 17.94 & 28.3 & 81 & 48.7 & 66.5 & 24.32 & 24.8 & 36.62 & 79.46 & 54 & 64 & 64.1 & 62.4 \\
\hline
\end{tabular}

The resistance of the sixteen group furrow opener was simulated. Application of intuitive analysis of uniform design, we could get less small resistance in number four furrow opener. It would back into the soil effect is good, groove is more smooth. It could provide the new method for the design of the furrow opener of core ploughshare.

\section{Furrow opener soil bin test equipment and test program}

\section{Test equipment}

Test apparatus was composed of micro soil bin and test equipments in figure 3. The horizontal force and vertical force of the working object were measured by two-dimensional force sensor and dynamic strain meter.

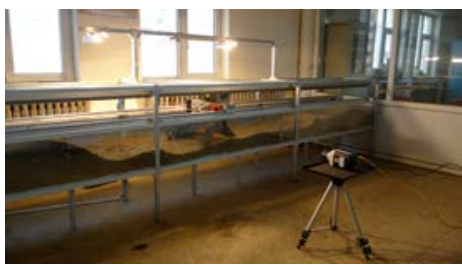

\section{Test program}

Figure 3 The test bench of the glass soil bin

In this experiment, five factors were selected such as the width of the opener, the penetrating clearance angle, the slope Angle, velocity and the moisture content. The soil moisture content is more difficult to control. It would change in the process of test. So, the level number of moisture content was two and the level numbers of the rest factors were eight in the experimental design. We selected the mix design method. The table of factor levels was shown in Table 4

Table 4 The table of factor levels

\begin{tabular}{|c|c|c|c|c|}
\hline width $(\mathrm{cm})$ & penetrating clearance angle $\quad\left({ }^{\circ}\right)$ & slope angle $\left({ }^{\circ}\right)$ & velocity $(\mathrm{m} / \mathrm{s})$ & moisture content (\%) \\
\hline 40 & 15 & 45 & 0.25 & 6 \\
\hline 50 & 20 & 50 & 0.35 & 19 \\
\hline 60 & 25 & 55 & 0.45 & \\
\hline 70 & 30 & 60 & 0.55 & \\
\hline 80 & 35 & 65 & 0.65 & \\
\hline 90 & 40 & 70 & 0.75 & \\
\hline 100 & 45 & 75 & 0.85 & \\
\hline 110 & 50 & 80 & 0.95 & \\
\hline
\end{tabular}

\section{The experimental results and analysis}

According to the experimental scheme, the different parameters of the opener is placed in the soil bin test bench was tested, and recorded the working resistance of opener is working with the soil and the movement of the working parts. 


\section{The working resistance and power consumption measurement in the furrow opener}

We would record the resistance in the working process of the furrow opener by the two-dimensional sensor and the dynamic strain meter. It was shown in figure 4. Due to the horizontal and vertical resistance is smaller influence on the test. Analysis is negligible.

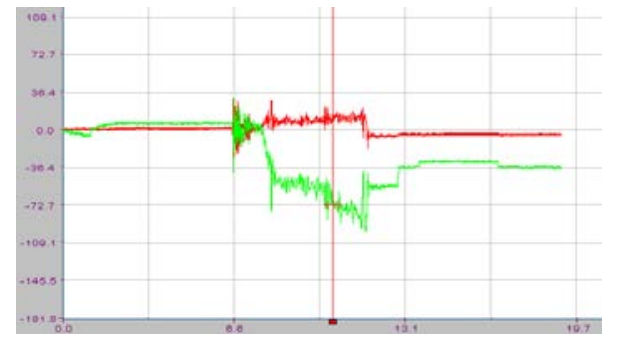

Figure 4 The diagram of the furrowing resistance

We selected the five numbers in relatively stable furrowing resistance area. The average was the test results. At the same time, the energy consumption is an important index to assess if the furrow opener was good. The energy consumption is ${ }^{[6]}$ :

$$
\eta=\frac{s}{d}
$$

Then, $\mathrm{s}$ is the furrowing area. $\mathrm{d}$ is the furrowing width. The furrow shape was measured by the homemade furrowed surveying and mapping unit in this paper. The furrow width could be measured directly. The experimental results were shown in Table 5. The operation quality of the furrow opener would be influenced by the horizontal resistance and the energy consumption. So, we adopted the method of weighted to analyze the test results in this experiment. The horizontal resistance of the furrow opener accounted for $70 \%$ of the results. The energy consumption accounted for $30 \%$ of the results.

Table 5 The test results table of the furrow opener

\begin{tabular}{cccccc}
\hline $\begin{array}{c}\text { test } \\
\text { number }\end{array}$ & furrowing area $\left(\mathrm{cm}^{2}\right)$ & width $(\mathrm{cm})$ & energy consumption & horizontal resistance $(\mathrm{N})$ & result of weighted \\
\hline 1 & 20 & 11.5 & 1.74 & 21.94 & 15.88 \\
2 & 20 & 11 & 1.82 & 21.7 & 15.74 \\
3 & 19 & 10 & 1.9 & 22.48 & 16.31 \\
4 & 19 & 10.5 & 1.81 & 7.94 & 6.1 \\
5 & 18 & 14 & 1.29 & 18.34 & 13.23 \\
6 & 25 & 15 & 1.67 & 70.9 & 50.13 \\
7 & 30 & 15 & 2 & 38.66 & 27.66 \\
8 & 30 & 14.5 & 2.07 & 56.5 & 40.17 \\
9 & 18 & 11.5 & 1.57 & 14.32 & 10.5 \\
10 & 25 & 11.5 & 2.17 & 14.8 & 11.01 \\
11 & 28 & 12 & 2.33 & 26.62 & 19.33 \\
12 & 27 & 12 & 2.25 & 69.46 & 49.3 \\
13 & 27 & 14.5 & 1.86 & 44.02 & 31.37 \\
14 & 25 & 14.5 & 1.72 & 54.44 & 38.62 \\
15 & 31 & 15 & 2.07 & 54.12 & 38.51 \\
16 & 30 & 16 & 1.88 & 52.4 & 37.24 \\
\hline
\end{tabular}

The weighted analysis showed that the horizontal resistance and energy consumption is relatively small in the furrow opener of the number four. That is the best design scheme.

\section{The measure of the movement of soil particles}

Due to the soil color was deeper, we were not convenient to observe the change of the underlying soil. We titled the fertilizer with color on the surface soil so that the high-speed cameras could record open the process of furrowing. When the furrow opener was narrower, the back soil of the furrow opener is relatively quickly. But it was easy to cause bottom uneven in figure 5. 

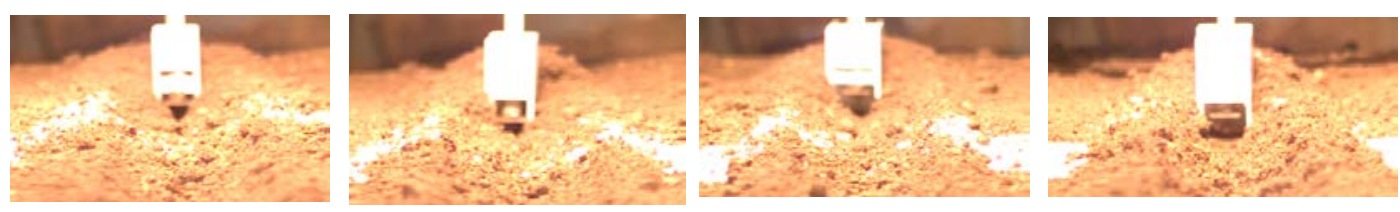

Figure 5 The assignments figure of the relatively narrow furrow opener

When the width, the penetrating clearance angle and the slope angle were all larger, the furrowing is easy to cause the soil is too high. The surface soil would fall in furrow. When opener was wide, the bottom was relatively flat in figure 6 . But the performance of back soil was poor.
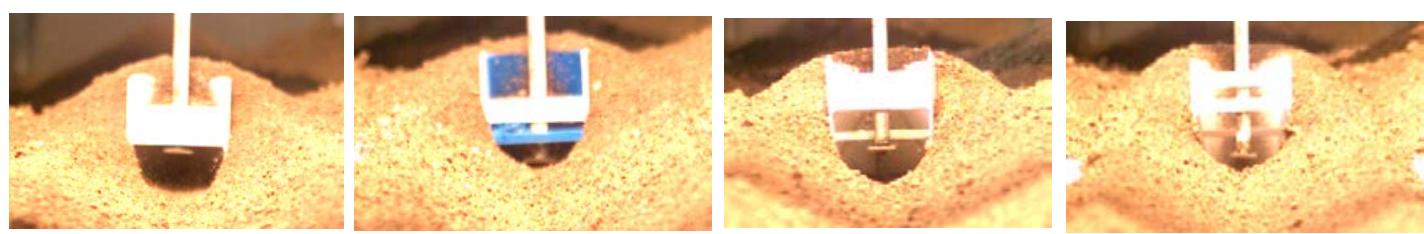

Figure 6 The assignments figure of the relatively wide furrow opener

The results of tests compared with discrete element simulation showed that both had the good correlation. The rule of the resistance was consistent. The main reasons for the deviation were two points. One is that the soil model is relatively complex. Some parameters could only be set with experience. The other is that the soils were hardening due to the use of a large number of chemical fertilizer in the soil bin.

\section{Conclusions}

We determined the design parameters and the level of the furrow opener of core ploughshare and finished 3D modeling and discrete element simulation. We also process the experiment analysis by the method of uniform design.

With glass soil bin and high-speed camera technology, we carried out experimental study of opener working process, providing an effective testing methods for the study of opener and soil movement .

Through the simulation analysis and the bench test, we could get a set of design scheme of the furrow opener of core ploughshare core using in Jilin province in central region.

\section{References}

[1] Chinese Academy of Agricultural Mechanization Sciences Agricultural machinery design manual (volume one) Beijing: China Machine Press 2007

[2] Wang Guoqiang,Hao Wanjun,Wang Jixin. Discrete element method and its practice in EDEM. Northwestern Polytechnical University Press, 2010.

[3] Tang Qiyi .DPS The DPS data processing system (Volume II). Modern statistics and data mining. Beijing: Science Press, 2013

[4] Zhao Xuanmin . Design of Experiment. Beijing: Science Press, 2006

[5] Gebresenbet G; Johnson H. Performance of seed drill coulters in relation to speed, depth and rake angles [J]. Journal of Agricultural Engineering Research,1992,52(2): 121-145.

[6] Wang Yanlong. Research on Opener Resistance Test and Ditching Performance Paddy Soil Conditions[ D].Nanjing Agricultural University.2012 